\title{
OCCUPATIONAL HEALTH SURVEILLANCE: PULMONARY FUNCTION TESTING AND OXIDATIVE STRESS AMONG PHOTOCOPYING WORKERS IN PAKISTAN
}

\author{
Houda Javed ${ }^{1}$, Nadia Ghani ${ }^{1}$, Natasha Ghani ${ }^{2}$, Ammara Fatima ${ }^{1}$ \\ ${ }^{1}$ Lahore College for Women University, Lahore, Pakistan \\ Department of Environmental Science \\ ${ }^{2}$ Children's Hospital and Institute of Child Health, Lahore, Pakistan \\ Neurological Department
}

\begin{abstract}
Background: The photocopying occupation contributes to various health issues in workers. Elevated levels of oxidative stress have been found to be associated with respiratory problems in occupational workers. The intention of the current research is to evaluate the association between the pulmonary function parameters, a biomarker of oxidative stress, and the photocopying occupation in Lahore, Pakistan. Material and Methods: The study was performed on a group of photocopying operators $(\mathrm{N}=100)$ and a control group $(\mathrm{N}=100)$. A structured questionnaire was developed to gather the demographic attributes. Lung function testing was done with the spirometer. The blood lipid peroxides level, as thiobarbituric acid reactive substances (TBARS), was assessed spectrophotometrically. Results: A statistically significant reduction was found in the pulmonary function parameters as compared to the control group. In the study group, the prevalence of respiratory symptoms, including cough (31\%), sneezing (18\%), wheezing (9\%) and breathing issues (19\%), was high as compared to the control group. A significantly higher plasma TBARS concentration was observed in the photocopying workers. A negative correlation prevailed between FVC $(-0.081)$, FVC\% predicted $(-0.038)$ and $\mathrm{FEV}_{1}(-0.043)$, and the duration of exposure. Conclusions: The study showed that the occupational exposure could have a significant effect on the normal pulmonary function and the oxidative potential of well-being. The profound emissions in the vicinity of photocopying centers may be responsible for the variations in the pulmonary function parameters and oxidative stress. Med Pr. 2019;70(4):403-10

Key words: oxidative stress, lipid peroxidation, malondialdehyde, pulmonary function test, toner, photocopying machines
\end{abstract}

Corresponding author: Houda Javed, Lahore College for Women University, Department of Environmental Science,

Jail Road 65, 54000 Lahore, Pakistan, e-mail: houdajaved@yahoo.com

Received: September 19, 2018, accepted: December 12, 2018

\section{INTRODUCTION}

Air pollution is a potential cause of acute and chronic health effects, ranging from slight upper respiratory tract irritation to chronic heart and lung diseases, chronic bronchitis in adults and acute pulmonary infections in children. It also aggravates the previously experienced symptoms of lung and heart diseases, asthma and lung cancer [1]. Chronic respiratory diseases have been found to be associated with long-term exposure to air pollution [2]. In the working environment, exposure to respirable dust particles is the prospective risk factor associated with long-term pulmonary illnesses. In the occupational environment, workers are prone to several pulmonary disorders [3]. Photocopying machines are the main source of indoor air pollution, involving the emission of ozone, volatile as well as semi-volatile organic compounds. Oxides of nitrogen, particles in the size of nano-range, electromagnetic radiations in the lower frequency range, UV light and certain metals, i.e., arsenic and selenium, have also been reported [4].

Air containing excessive particulate matter, volatile organic compounds and carbon monoxide exerts influence on diverse symptoms, like asthma aggravation, intensified respiratory symptoms, a declined lung function, an increased use of medicinal products, as well as hospital admittance [5]. Upon inhalation, particulate matters penetrate extensively into the lungs and get deposited in the alveolar sacs. The settlement of the particles in these sacs triggers inflammatory responses, and ultimately results in the activation of macrophages and acute inflammation [6]. The documented peak particle number concentration of nano-particles in the photocopying environment is $1 \times 10^{8}$ particles $/ \mathrm{cm}^{3}$, owing to an elevated output and persistent operation of machines. Furthermore, photocopying machines are intermittently accommodated in confined spaces without the adequate ventilation, making the condition even worse [7]. 
Various engineered nanoparticles that are present in toners, including titanium, fumed silica and iron oxide, turn out to be airborne particles. The chemical configuration of airborne particles is composite, and it comprises substantial elements and analytes of toners, inclusive of semi volatile organic compounds, metals, elemental and organic carbon. The organic content of the aerosol encompasses $50 \%$ to $70 \%$ of the aggregate mass whereas the chemistry is not entirely distinctive and likely to alter with toner formulation [8].

The primary component of a photocopying machine is the toner which generally consists of a resin, i.e., a copolymer of acrylates and styrene (approx. 55\%), a pigment, i.e., iron oxides (approx. 50\%), and an auxiliary anti-caking agent, i.e., amorphous silica (approx. 3\%). Upon heating, the resin exhibits the function of fixing the particles of the pigment to the paper. The particles of the toner with an aerodynamic diameter of 6-8 $\mu \mathrm{m}$ [9] accelerate the intense penetration into the human respiratory system. Extremely fine aerosol particles released from the paper in photocopying machines constitute another source of indoor emissions [10].

In steelworkers with smoking habits, forced vital capacity (FVC) as well as forced expiratory volume in $1 \mathrm{~s}$ $\left(\mathrm{FEV}_{1}\right)$ decreased in response to exposure to respirable dust at average levels [11]. In acute respiratory distress syndrome, the lipid peroxidation level, expressed as arterial malondialdehyde (MDA) concentration, significantly increased [12]. Reduced pulmonary functions (FVC, $\mathrm{FEV}_{1}, \mathrm{FEV}_{1} / \mathrm{FVC}$, as well as peak expiratory flow $[\mathrm{PEF}])$ were observed in the exposed cement factory individuals as compared to the unexposed workers. The exposed workers reported periodic and prolonged phlegm, bronchitis, wheeze, breathlessness, asthma and cough [13].

Lipid peroxidation is considered to be one of the most discernible demonstrations of oxidative stress [14]. The generation of reactive oxygen species can be observed by numerous biomarkers. However, malondialdehyde is the most frequently studied product in relation to the peroxidation of the polyunsaturated fatty acids and the elevation of oxidative stress [15]. The smoking habit has been found to be significantly correlated with the levels of lipid peroxidation as determined by the thiobarbituric acid reactive substances (TBARS) concentration [16].

In general, the intent of this research study was to assess the health effects encountered in relation to the occupation in question, by examining the pulmonary function parameters of the exposed workers and analyzing the effect on lipid peroxidation as an oxidative stress marker with the functional ability to prevent pulmonary disorders and stress in these workers.

\section{MATERIAL AND METHODS}

\section{Experimental design}

A cross-sectional study was conducted in January-September 2017 in accordance with the Helsinki Declaration, upon obtaining an approval from the Institutional Ethical Committee of Lahore College for Women University. The spirometry test was performed on photocopying operators as well as toner fillers $(\mathrm{N}=100)$, and a comparison was made with the control subjects $(\mathrm{N}=100)$. The photocopying operators and toner filling operators, aged 17-65, were included in the study, whereas individuals with previously known chronic illnesses were excluded. In order to scrutinize the effect of the smoking habit, the subjects were classified either as smokers or non-smokers. The subjects were categorized into 2 main groups. All the subjects provided their informed written consent prior to inclusion in the study. The intention of the study was well notified to all the participants. Information was gathered regarding the demographic attributes (age, medical history, socio-economic status, smoking and alcohol consumption, etc.), along with occupation-related particulars (nature of the job, years of exposure, etc.). The same socio-economic status factor was duly considered in the experimental and control subjects.

\section{Pulmonary function test}

Pulmonary function evaluation was done using a portable handheld spirometer, model: Spirotron (MDX Instruments, USA). The general specifications for the performance as well as interpretation of the pulmonary function test were followed [17-20]. The pulmonary function indices documented were the FVC, $\mathrm{FEV}_{1}$ and $\mathrm{FEV}_{1} / \mathrm{FVC}$ ratios. All the readings were in the units of liters and percentage predicted values.

\section{Lipid peroxidation assay}

Venous blood $(3 \mathrm{ml})$ was collected from the subjects. The blood samples of the experimental as well as control subjects were collected in tubes containing ethylenediaminetetraacetic acid (EDTA) as an anticoagulant. The tubes with blood samples were centrifuged at $3300 \mathrm{rpm}$ for $5 \mathrm{~min}$ in order to separate the plasma. The samples underwent the analysis immediately after separation. For the determination of oxidative stress, the most widely acceptable thiobarbituric acid reactive 
substances assay that quantifies the concentration of malondialdehyde, a product formed as a result of degradation of unstable lipid peroxides [21], was exercised. After centrifugation, the plasma (1 ml) was collected. Normal saline $(1 \mathrm{ml})$ was added into it, and then also $1 \mathrm{ml}$ of trichloroacetic acid (TCA-25\%). The entire mixture underwent centrifugation at a speed of $2000 \mathrm{rpm}$ for $20 \mathrm{~min}$. The addition of trichloroacetic acid to the plasma resulted in the sedimentation of protein in the mixture. The supernatant that was protein free was collected to another centrifuge tube. To the protein free supernatant, $0.25 \mathrm{ml}$ of thiobarbituric acid (TBA) at a concentration of $1 \%$ was then added, and the mixture was boiled in temperature of $95^{\circ} \mathrm{C}$ for $1 \mathrm{~h}$. This yielded a pinkcolored product. The intensity of the color pink was de- termined spectrophotometrically at $532 \mathrm{~nm}$ [22]. The equivalents of malondialdehyde were quantified using an extinction coefficient of $1.56 \times 10^{5} \mathrm{M}^{-1} \mathrm{~cm}^{-1}$. The expression of the results was done as $\mu \mathrm{M} / 1$ [23].

\section{Statistical analysis}

All statistical calculations were performed using SPSS 13.0 (SPSS Inc., USA) for Windows. Descriptive statistical tests were performed to assess the mean and standard deviations of the quantitative variables. For the pulmonary function indices and the total lipid peroxidation level in the plasma, both mean and standard deviations were calculated for each parameter. Student t-test or Mann-Whitney U test was used to compare the mean values of the pulmonary function data and the oxida-

Table 1. Baseline attributes of the experimental and control subjects

\begin{tabular}{|c|c|c|c|}
\hline Attributes & Experimental group & Control group & $\mathrm{p}$ \\
\hline male & 100 & 100 & \\
\hline female & 0 & 0 & \\
\hline Age [years] $(\mathrm{M} \pm \mathrm{SD})$ & $28.19 \pm 7.58$ & $31.08 \pm 10.97$ & $0.175 \dagger$ \\
\hline range & $15.81-35.16$ & $14.88-33.87$ & \\
\hline Smoking [n] & & & - \\
\hline yes & 29 & 24 & \\
\hline $\mathrm{M} \pm \mathrm{SD}$ & $6.5 \pm 6.54$ & - & \\
\hline range & $0.5-24.0$ & & \\
\hline Education [n] & & & - \\
\hline primary & 13 & 16 & \\
\hline secondary & 30 & 31 & \\
\hline higher & 57 & 53 & \\
\hline FVC [1] $(\mathrm{M} \pm \mathrm{SD})$ & $2.62 \pm 0.66$ & $2.85 \pm 0.94$ & $0.261 \dagger$ \\
\hline FVC\% predicted [\%] $(\mathrm{M} \pm \mathrm{SD})$ & $66.39 \pm 17.62$ & $83.57 \pm 11.72$ & $0.000 \dagger^{* *}$ \\
\hline
\end{tabular}

$\mathrm{FEV}_{1} / \mathrm{FVC}$ ratio - the forced expiratory volume in $1 \mathrm{~s}$ to forced vital capacity ratio, TBARS - thiobarbituric acid reactive substances.

$\dagger$ Mann-Whitney U Test.

${ }^{*} \mathrm{p}$-value significant at the level of $\mathrm{p}<0.05$.

${ }^{* *} \mathrm{p}$-value significant at the level of $\mathrm{p}<0.01$. 
Table 2. Physical ailments in the experimental and control subjects

\begin{tabular}{|c|c|c|c|c|}
\hline Symptom & $\begin{array}{l}\text { Experimental group } \\
{[\mathrm{n}]}\end{array}$ & $\begin{array}{c}\text { Control group } \\
{[\mathrm{n}]}\end{array}$ & $\mathrm{OR}(\mathrm{CI})$ & $\mathrm{p}$ \\
\hline Headache & 30 & 11 & $3.467(1.624-7.403)$ & $0.001 \dagger^{* *}$ \\
\hline Fatigue & 39 & 12 & $4.688(2.271-9.678)$ & $0.000 \dagger^{* *}$ \\
\hline Nasal irritation & 10 & 2 & $5.444(1.161-25.522)$ & $0.033 \dagger^{*}$ \\
\hline Eye irritation & 20 & 3 & $8.083(2.318-28.188)$ & $0.000 \dagger^{* *}$ \\
\hline Skin irritation & 8 & 1 & $8.608(1.056-70.172)$ & $0.035 \dagger \dagger^{*}$ \\
\hline Throat irritation & 11 & 5 & $2.348(0.785-7.026)$ & $0.118 \dagger$ \\
\hline Dizziness & 15 & 7 & $2.345(0.912-6.027)$ & $0.071 \dagger$ \\
\hline Insomnia & 11 & 5 & $2.348(0.785-7.026)$ & $0.118 \dagger$ \\
\hline Poor memory & 9 & 3 & $3.198(0.839-12.183)$ & $0.134 \dagger \dagger$ \\
\hline Poor appetite & 11 & 2 & $6.056(1.307-28.074)$ & $0.018 \dagger^{*}$ \\
\hline Vision problem & 10 & 6 & $1.741(0.608-4.987)$ & $0.297 \dagger$ \\
\hline Hearing problem & 03 & 1 & $3.062(0.313-29.949)$ & $0.621 \dagger \dagger$ \\
\hline Coughing & 31 & 9 & $4.543(2.030-10.165)$ & $0.000 \dagger^{* *}$ \\
\hline Sneezing & 18 & 11 & $1.776(0.792-3.984)$ & $0.160 \dagger$ \\
\hline Wheezing & 9 & 4 & $2.734(0.706-7.978)$ & $0.251 \dagger \dagger$ \\
\hline Phlegm production & 20 & 5 & $4.75(1.706-13.227)$ & $0.001 \dagger^{* *}$ \\
\hline Chest pain & 13 & 4 & $3.586(1.127-11.413)$ & $0.040 \dagger \dagger^{*}$ \\
\hline Shortness of breath & 19 & 7 & $3.116(1.246-7.792)$ & $0.012 \dagger^{* *}$ \\
\hline
\end{tabular}

$\dagger$ Chi square test.

$\dagger \dagger$ Fisher's exact test.

${ }^{*} \mathrm{p}$-value significant at the level of $\mathrm{p}<0.05$.

${ }^{* *} \mathrm{p}$-value significant at the level of $\mathrm{p}<0.01$.

tive stress marker between the experimental and control subjects. To analyze the interrelationship between the pulmonary function data as well as the oxidative stress biomarker, correlation coefficients were determined. The pulmonary function data was expressed in percentage terms of the predicted values as well. The p-value of $<0.05$ was considered to be significant. One-way analysis of variance was performed to evaluate the significance of the factors on the dependent variables. All confidence intervals (CI) were calculated at a 95\% level.

\section{RESULTS}

The demographic patterns, pulmonary function indices and lipid peroxidation as a marker of oxidative stress are presented in Table 1. The workers were monitored in terms of the respiratory symptoms experienced, i.e., cough (31\%), sneezing (18\%), wheezing (9\%) and breathing problems (19\%), as well as other health issues, as demonstrated in Table 2. Among smokers in the experimental group, the prevalence of coughing, sneezing, wheezing, phlegm production, chest pain and shortness of breath was calculated, in percentage terms, as $20.69 \%, 24.14 \%, 6.90 \%, 17.24 \%, 24.14 \%$ and $17.24 \%$, respectively, whereas among smokers in the control group, the prevalence of the same health problems amounted to $4.17 \%, 12.5 \%, 4.17 \%, 8.33 \%, 4.17 \%$ and $4.17 \%$, respectively. For coughing, sneezing, wheezing, phlegm production, chest pain and shortness of breath, the prevalence, in percentage terms, was determined at $35.21 \%, 15.49 \%, 9.86 \%, 21.13 \%, 8.45 \%, 19.72 \%$, respectively, in the experimental study subjects with no smoking habits, whereas in the non-smoker control study subjects, the percentage rates were found to be $10.53 \%$, $10.53 \%, 3.95 \%, 3.95 \%, 3.95 \%$ and $7.89 \%$, respectively, for the above-mentioned health problems. The association between the $\mathrm{FVC}, \mathrm{FVC} \%$ predicted, $\mathrm{FEV}_{1}$ and $\mathrm{FEV}_{1} \%$ predicted was found to be statistically significant $(\mathrm{p}<0.05)$ with the smoking habit (Table 3$)$.

With the increase in age, a reduction in the pulmonary function parameters was observed in both the experimental and control subjects. A negative correla- 


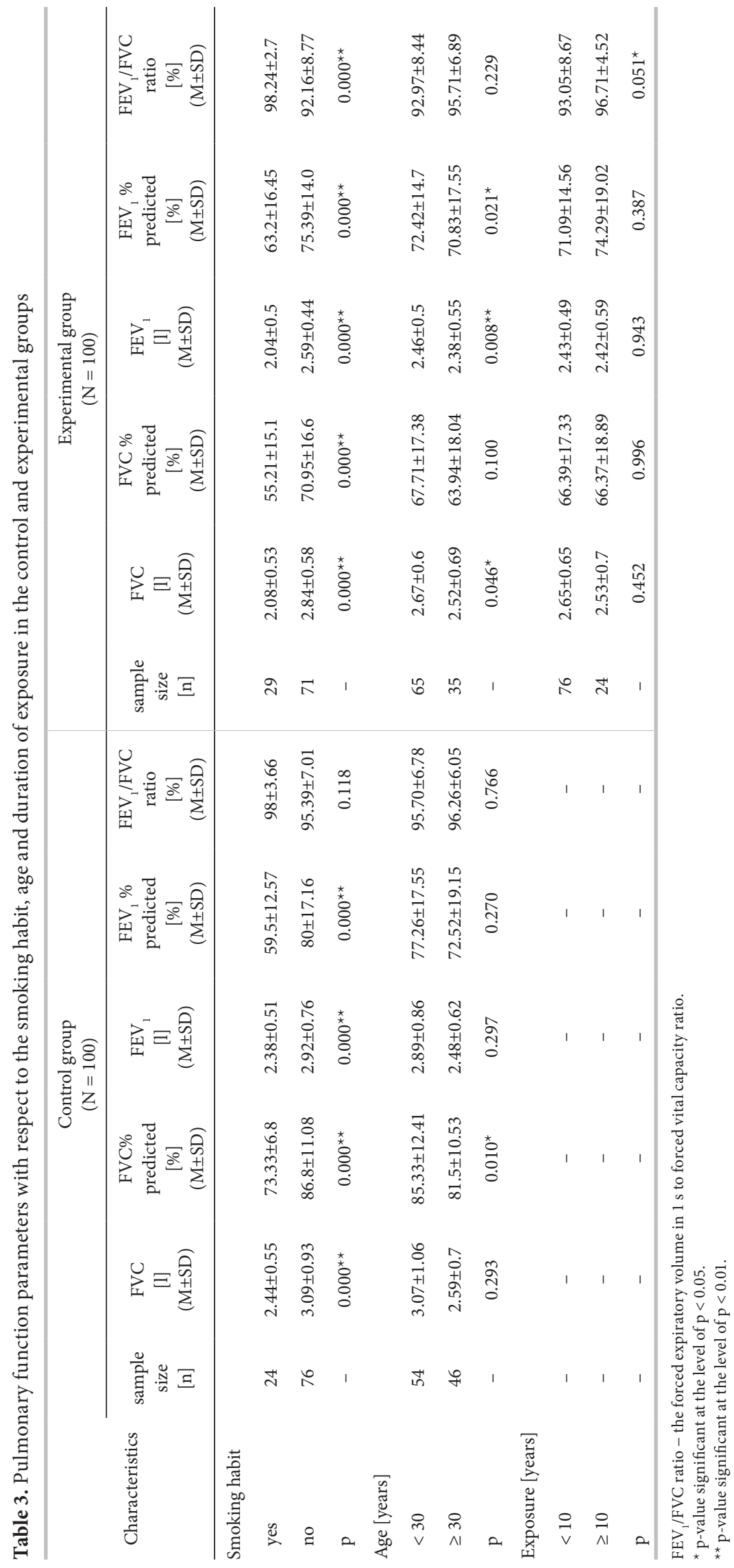


Table 4. Correlation coefficient between the pulmonary function data and plasma thiobarbituric acid reactive substances (TBARS) as malondialdehyde (MDA) in the experimental and control groups

\begin{tabular}{|c|c|}
\hline Parameter & Plasma TBARS \\
\hline \multicolumn{2}{|l|}{ FVC\% predicted [\%] } \\
\hline experimental group & $-0.221^{\star}$ \\
\hline control group & $-0.284^{\star}$ \\
\hline \multicolumn{2}{|l|}{$\mathrm{FEV}_{1} \%$ predicted [\%] } \\
\hline experimental group & $-0.178^{\star}$ \\
\hline control group & $-0.336^{\star}$ \\
\hline
\end{tabular}

* The correlation is significant at the level of 0.05 .

tion was found to exist between age and FVC $(-0.167)$, FVC\% predicted (-0.12), $\mathrm{FEV}_{1}(-0.14)$ and $\mathrm{FEV}_{1} \%$ predicted (-0.07). Age was found to be statistically significant $(\mathrm{p}<0.05)$ in the case of forced vital capacity $(\mathrm{l})$ and the first forced expiratory volume (l). A reduction in the pulmonary function parameters was observed with the increasing duration of exposure. A negative correlation was revealed between FVC, FVC\% predicted and $\mathrm{FEV}_{1}$, and the duration of exposure, with the values amounting to $-0.081,-0.038,-0.043$, respectively. However, it was not found to be statistically significant $(\mathrm{p}>0.05)$, as shown in Table 3.

The severity of airflow obstruction, on the basis of the percent predicted first forced expiratory volume ( $\mathrm{FEV}_{1} \%$ predicted), was subcategorized into $\geq 80$ as mild, $50-79$ as moderate, $30-49$ as severe, and $<30$ as very severe [20]. Following the specified categorization, the present study revealed that $13.92 \%$ of the experimental subjects fell in the mild category, $63.29 \%$ in the moderate category, $3.79 \%$ in the severe category, and $0 \%$ in the very severe category of airflow obstruction.

The quantification of the ventilatory function is very useful. The obstructive ventilatory defect is indicated by the limitation in the airflow, and characterized by reduced $\mathrm{FEV}_{1}$, normal or reduced $\mathrm{FVC}$, along with reduced $\mathrm{FEV}_{1} / \mathrm{FVC}$. The lower limit of the $\mathrm{FEV}_{1} / \mathrm{FVC}$ ratio is around $70-75 \%$. In the case of restrictive ventilator defects, the $\mathrm{FEV}_{1} / \mathrm{FVC}$ ratio remains normal or typically high with reduced $\mathrm{FEV}_{1}$ as well as FVC. A reduced FVC ratio, along with a lower $\mathrm{FEV}_{1} / \mathrm{FVC}$ ratio, is an indicator of a mixed ventilator defect $[24,25]$. In the current study, spirometry results revealed that $44 \%$ of the respondents in the experimental group, and $73 \%$ of the subjects in the control group, had a normal ventilatory function. In the experimental study subjects, the percentage values for restrictive, obstructive and mixed ventilatory defects were determined at $47 \%, 5 \%$ and $4 \%$, respectively. In the control subjects, the percentage values for the above-mentioned ventilatory defects were found to be $24 \%, 2 \%$ and $1 \%$, respectively.

The mean values of the oxidative stress marker in the form of the total lipid peroxides level (TBARS $[\mu \mathrm{M} / 1]$ ), as determined in the plasma of the experimental and control subjects, amounted to $2.25 \pm 0.60$ and $1.19 \pm 0.26$, respectively. The present study outlines the statistically significant association between the levels of plasma lipid peroxides as TBARS, and the smoking status and the duration of exposure $(\mathrm{p}<0.05)$. A negative correlation exists between the predicted percentage of forced vital capacity, the predicted percentage of forced expiratory volume and the levels of plasma lipid peroxides (TBARS $[\mu \mathrm{M} / 1]$ ), as shown in Table 4.

\section{DISCUSSION}

A statistically significant elevated incidence of nasal blockage, breathing problems and sputum production was observed among the photocopying operators, as compared to the control group. A higher prevalence of restrictive patterns were also found, as compared to the controls. However, a non-significant result was observed in the percent predicted values of $\mathrm{FEV}_{1}, \mathrm{FVC}$, $\mathrm{FEV}_{1} / \mathrm{FVC}$, PEF, and the mean forced expiratory flow between $25 \%$ and $75 \%$ of forced vital capacity $\left(\mathrm{FEF}_{25-75}\right)$ between the control group and the workers involved in the photocopying operation. The level of TBARS in the serum was found to be statistically elevated in the photocopying workers [26].

The correlation between the age factor and the abnormality in the pulmonary function parameters was found to be statistically significant [27]. Tobacco smoke contains several chemical compounds, and there is an 
association between the smoking habit and the oxidative stress in lungs [28].

During photocopying operations, the workers are exposed to emanated particles by a direct route [10]. Photocopying workers are more prone to pulmonary function impairments, since an increased personal exposure to ultrafine particles and particulate matter 2.5 has been found in this occupational group. A consequent exposure has manifested a remarkable alleviation in $\mathrm{FVC}, \mathrm{FEV}_{1} \%$ predicted, $\mathrm{FVC} \%$ predicted and $\mathrm{FEV}_{1} /$ FVC\%, thereby exhibiting a significant association between personal exposure and pulmonary functions [29].

Oxidative stress elevation has been found in the case of photocopying workers [30,31]. Short-term exposures to the emissions from photocopying machines have been found to cause high oxidative stress as well as inflammatory reactions in their local airways [32].

\section{CONCLUSIONS}

The current study was designed to assess the association between the pulmonary function indices, oxidative stress and the photocopying occupation. In the present research, a significant difference was observed in both the pulmonary function indices and the lipid peroxidation level in the photocopying workers. The individuals encountering exposure to toner dust during cleaning and maintenance operations reported more respiratory symptoms. The insufficient data availability leads to the worst situation. A significant negative correlation exists between FVC\% predicted, FEV1\% predicted and Plasma TBARS. Much attention is required to be given to such issues in order to mitigate the adverse health effects.

\section{ACKNOWLEDGMENTS}

The authors are thankful to the Chairperson of the Department of Environmental Science for administrative support during the study, and also to the laboratory staff of the Department.

\section{REFERENCES}

1. Kampa M, Castanas E. Human health effects of air pollution. Environ Pollut. 2008;151(2):362-7, https://doi.org/10.1016/ j.envpol.2007.06.012.

2. Groneberg-Kloft B, Kraus T, Mark A, Wagner U, Fischer A. Analysing the causes of chronic cough: relation to diesel exhaust, ozone, nitrogen oxides, sulphur oxides and other environmental factors. J Occup Med Toxicol. 2006;1:6, https:// doi.org/10.1186/1745-6673-1-6.
3. Beckett WS. Occupational respiratory diseases. N Engl J Med. 2000;342(6):406-13, https://doi.org/10.1056/NEJM200002 103420607.

4. Bar-Sela S, Shoenfeld Y. Photocopy machines and occupational anti-phospholipid syndrome. Isr Med Assoc J. 2008;10(1):52-4.

5. Utell MJ, Frampton MW. Acute health effects of ambient air pollution: the ultrafine particle hypothesis. J Aerosol Med. 2000;13(4):355-9, https://doi.org/10.1089/jam.2000. 13.355 .

6. Oberdorster G, Finkelstein JN, Johnston C, Gelein R, Baggs R, Elder A. Ultrafine particles as inducers of acute lung injury: mechanisms and correlation with age and disease. Res Rep Health Eff Inst. 2000;96:1-88.

7. Lee CW, Hsu DJ. Measurements of fine and ultrafine particles formation in photocopy centers in Taiwan. Atmos Environ. 2007;41(31):6598-609, https://doi.org/10.1016/ j.atmosenv.2007.04.016.

8. Bello D, Martin J, Santeufemio C, Sun Q, Lee Bunker K, Shafer M, et al. Physicochemical and morphological characterisation of nanoparticles from photocopiers: implications for environmental health. Nanotoxicology. 2013;7(5): 989-1003, https://doi.org/10.3109/17435390.2012.689883.

9. Kim SY, Kim Y, Byeon JH, Lee DY, Hwang J. Emission of submicron aerosol particles in operating a laser beam printer. Int J Precis Eng Manuf. 2009;10(5):33-6, https:// doi.org/10.1007/s12541-009-0090-4.

10. Wensing M, Kummer T, Riemann AW, Schwampe W. Emissions from electronic devices: examination of computer monitors and laser printers in a $1 \mathrm{~m} 3$ emission test chamber. In: International Society of Indoor Air Quality and Climate. The 9th International Conference on Indoor Air and Climate Proceedings; 2002 Jun 30-Jul 5; Monterey: 2002. p. 554-9.

11. Chen PC, Doyle PE, Wang JD. Respirable dust exposure and respiratory health in male Taiwanese steelworkers. Ind Health. 2006;44(1):190-9, https://doi.org/10.2486/indhealth.44.190.

12. Lichtenstern C, Hofer S, Mollers A, Synder-Ramos S, SpiesMartin D, Martin E, et al. Lipid peroxidation in acute respiratory distress syndrome and liver failure. J Surg Res. 2011; 168(2):243-52, https://doi.org/10.1016/j.jss.2009.10.028.

13. Al-Neaimi YI, Gomes J, Lloyd OL. Respiratory illness and ventilator function among workers at a cement factory in a rapidly developing country. Occup Med. 2001;51(6): 367-73, https://doi.org/10.1093/occmed/51.6.367.

14. Halliwell B, Gutteridge JMC. Role of free radicals and catalytic metal ions in human disease: an overview. Methods Enzymol. 1990;186:1-87, https://doi.org/10.1016/0076-68 79(90)86093-B. 
15. Del Rio D, Stewart AJ, Pellegrini N. A review of recent studies on malondialdehyde as toxic molecule and biological marker of oxidative stress. Nutr Metab Cardiovasc Dis. 2005;15(4):316-28, https://doi.org/10.1016/j.numecd.2005.05.003.

16. Pasupathi P, Chinnaswamy P, Saravanan G, Kumar US. Effect of chronic smoking on lipid peroxidation and antioxidant status in gastric carcinoma patients. Bangladesh Med Res Counc Bull. 2009;35(1):1-6, https://doi.org/10.3329/ bmrcb.v35i1.2132.

17. Miller MR, Crapo R, Hankinson J, Brusasco V, Burgos F, Casaburi R, et al. General considerations for lung function testing. Eur Respir J. 2005;26(1):153-61, https://doi.org/10. 1183/09031936.05.00034505.

18. Pellegrino R, Viegi G, Brusasco V, Crapo RO, Burgos F, Casaburi R, et al. Interpretative strategies for lung function tests. Eur Respir J. 2005;26(5):948-68, https://doi.org/10.11 83/09031936.05.00035205.

19. Miller MR, Hankinson J, Brusasco V, Burgos F, Casaburi R, Coates A, et al. Standardisation of spirometry. Eur Respir J. 2005;26(2):319-38, https://doi.org/10.1183/09031936.05. 00034805 .

20. Ranu H, Wilde M, Madden B. Pulmonary Function Tests. Ulster Med J. 2011;80(2):84-90.

21. Vaya J. Exogenous markers for the characterization of human disease associated with oxidative stress. Biochimie. 2013;95(3):578-84, https://doi.org/10.1016/j.biochi.2012. 03.005 .

22. Ilieva V, Nikolova G, Gadjeva V. Lipid peroxidation and catalase activities in patients with chronic obstructive pulmonary disease: A comparative study with other pulmonary diseases. Trakia J Sci. 2014;12(2):177-81.

23. Ali M, Rizvi TF, Perveen Z, Mishra GC, Kumar R, Kumar A. Lipid peroxidation as a biomarker for exposure of pesticides. Int J Adv Res. 2014;2(9):717-20.
24. Johns DP, Pierce R. Spirometry: The measurement and interpretation of ventilatory function in clinical practice. Melbourne: National Asthma Council; 1995, updated 2008. p. $1-24$.

25. Moore VC. Spirometry: step by step. Breathe. 2012;8(3): 233-40, https://doi.org/10.1183/20734735.0021711.

26. Elango N, Kasi V, Vembhu B, Poornima JG. Chronic exposure to emissions from photocopiers in copy shops cause oxidative stress and systematic inflammation among photocopiers in India. Environ Health. 2013;12(1):78, https:// doi.org/10.1186/1476-069X-12-78.

27. Dehghan F, Mohammadi S, Sadeghi Z, Attarchi M. Respiratory complaints and spirometric parameters in tile and ceramic factory workers. Tanaffos. 2009;8(4):19-25.

28. Doruk S, Ozyurt H, Inonu H, Erkorkmaz U, Saylan O, Seyfikli Z. Oxidative status in the lungs associated with tobacco smoke exposure. Clin Chem Lab Med. 2011;49(12): 2007-12, https://doi.org/10.1515/CCLM.2011.698.

29. Bahruddin NA, Jalaludin J, Praveena SM. PM2.5 \& UFP exposure and its association with respiratory health illness among photocopy workers in Selangor. Asia Pacific Environ Occup Health J. 2015;1(1):36-43.

30. Gadhia PK, Patel D, Solanki KB, Tamakuwala DN, Pithawala MA. A preliminary cytogenetic and haematological study of photocopying machine operators. Indian J Occup Environ Med. 2005;9(1):22-5, https://doi.org/10.4103/00 19-5278.16037.

31. Kleinsorge EC, Erben M, Galan MG, Barison C, Gonsebatt ME, Simoniello MF. Assessment of oxidative status and genotoxicity in photocopier operators: a pilot study. Biomarkers. 2011;16(8):642-8, https://doi.org/10.3109/13 54750X.2011.620744.

32. Khatri M, Bello D, Gaines P, Martin J, Pal AK, Gore R, et al. Nanoparticles from photocopiers induce oxidative stress and upper respiratory tract inflammation in healthy volunteers. Nanotoxicology. 2013;7(5):1014-27, https:// doi.org/10.3109/17435390.2012.691998

This work is available in Open Access model and licensed under a Creative Commons Attribution-NonCommercial 3.0 Poland License - http://creativecommons.org/licenses/by-nc/3.0/pl/deed.en. 